Research Article

\title{
The effect of erythropoietin on potassium levels during ischemia reperfusion injury in rats
}

\begin{abstract}
The aim of this experimental study was to examine the effect of erythropoietin on a rat model and particularly a hypoxia reoxygenation (HR) protocol. The effect of that molecule was studied biochemically using blood mean potassium (K) levels.

Materials and methods: 40 rats of mean weight $247.7 \mathrm{~g}$ were used in the study. Potassium levels were measured at 60minute (groups A and C) and at 120 minute (groups B and D) of reoxygenation. Erythropoietin (Epo) was administered only in groups C and D.

Results: Erythropoietin administration decreased the potassium levels insignificantly by $2.21 \% \pm 3.66 \% \quad(\mathrm{P}=0.5134)$. Reoxygenation time increased the potassium levels insignificantly by $3.58 \% \pm 3.63 \%(\mathrm{P}=0.3375)$. The interaction of erythropoietin administration and reoxygenation time increased the potassium levels insignificantly by $0.18 \% \pm 2.22 \%(\mathrm{P}=0.9338)$.

Conclusion: Erythropoietin administration, re-oxygenation time and their interaction have miscellaneous insignificant effects on potassium levels on the narrow context of 2 hours. Perhaps, a longer study time or a higher Epo dose may have clearer and significant effects.
\end{abstract}

Keywords: hypoxia, erythropoietin, potassium, re-oxygenation, ischemia reperfusion

\author{
Volume I Issue I - 2015
}

Tsompos C,' Panoulis C, ${ }^{2}$ TOutouzas K, ${ }^{3}$ Zografos $\mathrm{G}^{3}$ Papalois $\mathrm{A}^{4}$

'Department of Obstetrics \& Gynecology, Messolonghi County Hospital, Greece

${ }^{2}$ Department of Obstetrics \& Gynecology, Athens University, Greece

${ }^{3}$ Department of Surgery, Athens University, Greece

${ }^{4}$ Exprerimental Research Center ELPEN Pharmaceuticals, Greece

Correspondence: Tsompos C, Department of Obstetrics \& Gynecology, Messolonghi County Hospital, Etoloakarnania, Greece, Tel +46406657768,

Email constantinostsompos@yahoo.com

Received: September 30, 2015 | Published: December 30, 2015
Abbreviations: Epo, erythropoietin; rHuEPO, recombinant human erythropoietin; HPA, hypothalamo pituitary-adrenal

\section{Introduction}

Tissue hypoxia and reoxygenation (HR) remain the main causes of permanent or transient damage with serious implications on adjacent organs and certainly on patients health. ${ }^{1}$ Although important progress has been made regarding the usage of erythropoietin (Epo) in managing this kind of damages, satisfactory answers to fundamental questions have yet to be found. Fundamental questions such as by what velocity this factor should act at, when it should be administered and in which dosage. The particularly satisfactory action of Epo in stem blood cells recovery has been noted in several performed experiments. However, a few relative reports were found concerning Epo trial in HR experiments, not covering completely this particular matter. A meta-analysis of 15 published seric variables, ${ }^{2}$ coming from the same experimental setting, tried to provide a numeric evaluation of the Epo efficacy at the same endpoints (Table 1).

Table I The erythropoietin (Epo) influence $( \pm S D)$ on the levels of some seric variables concerning reperfusion (rep) time

\begin{tabular}{|c|c|c|c|c|c|c|c|c|}
\hline Variable & Ih rep & P-value & I.5h rep & P-value & 2h Rep & P-value & $\begin{array}{l}\text { Interaction of } \\
\text { Epo and rep }\end{array}$ & P-value \\
\hline $\begin{array}{l}\text { White Blood } \\
\text { Cells }\end{array}$ & $+24.01 \% \pm 13.38 \%$ & 0.1012 & $+22.09 \% \pm 9.11 \%$ & 0.0351 & $+20.17 \% \pm 12.94 \%$ & 0.0902 & $+14.63 \% \pm 5.40 \%$ & 0.008 \\
\hline Hematocrit & $+0.14 \% \pm 2.89 \%$ & 0.9626 & $-0.61 \% \pm 2.37 \%$ & 0.8072 & $-1.37 \% \pm 4.05 \%$ & 0.7485 & $+0.24 \% \pm 1.38 \%$ & 0.8586 \\
\hline $\begin{array}{l}\text { Mean } \\
\text { Corpuscular } \\
\text { Hemoglobin }\end{array}$ & $+0.01 \% \pm 1.29 \%$ & 0.9904 & $+0.67 \% \pm 0.80 \%$ & 0.3549 & $+1.34 \% \pm 1.08 \%$ & 0.1509 & $-0.36 \% \pm 0.47 \%$ & 0.443 \\
\hline $\begin{array}{l}\text { Platelet } \\
\text { Distribution } \\
\text { Width }\end{array}$ & $+1.60 \% \pm 0.80 \%$ & 0.0765 & $+1.36 \% \pm 0.58 \%$ & 0.0205 & $+1.13 \% \pm 0.74 \%$ & 0.1152 & $+0.37 \% \pm 0.37 \%$ & 0.0615 \\
\hline Platelet-Crit & $-16.47 \% \pm 10.40 \%$ & 0.0921 & $-13.74 \% \pm 7.01 \%$ & 0.0158 & $-11.01 \% \pm 7.34 \%$ & 0.0882 & $-6.88 \% \pm 3.69 \%$ & 0.0615 \\
\hline Urea & $+21.42 \% \pm 7.84 \%$ & 0.0115 & $+20.11 \% \pm 7.25 \%$ & 0.0059 & $+18.80 \% \pm 9.44 \%$ & 0.0709 & $+15.64 \% \pm 4.04 \%$ & 0.0003 \\
\hline Uric Acid & $+10.13 \% \pm 15.10 \%$ & 0.4917 & $+15.86 \% \pm 10.21 \%$ & 0.1408 & $+21.59 \% \pm 15.45 \%$ & 0.194 & $+9.33 \% \pm 6.16 \%$ & 0.1264 \\
\hline
\end{tabular}




\begin{tabular}{|c|c|c|c|c|c|c|c|c|}
\hline Variable & Ih rep & P-value & I.5h rep & P-value & 2h Rep & P-value & $\begin{array}{l}\text { Interaction of } \\
\text { Epo and rep }\end{array}$ & P-value \\
\hline Total Protein & $-0.02 \% \pm 2.47 \%$ & 0.9904 & $-1.27 \% \pm 1.51 \%$ & 0.3721 & $-2.52 \% \pm 2.03 \%$ & 0.1509 & $-0.68 \% \pm 2.48 \%$ & 0.443 \\
\hline $\begin{array}{l}\text { Alkaline } \\
\text { Phosphatase }\end{array}$ & $+0.20 \% \pm 18.57 \%$ & 0.9904 & $+10.70 \% \pm 12.78 \%$ & 0.3549 & $+21.20 \% \pm 17.11 \%$ & 0.1509 & $+5.79 \% \pm 7.72 \%$ & 0.443 \\
\hline $\begin{array}{l}\text { Acid } \\
\text { Phosphatase }\end{array}$ & $+0.06 \% \pm 5.79 \%$ & 0.9904 & $+3.11 \% \pm 3.71 \%$ & 0.3172 & $+6.16 \% \pm 4.97 \%$ & 0.1509 & $+1.68 \% \pm 2.23 \%$ & 0.443 \\
\hline CPK & $+0.15 \% \pm 14.09 \%$ & 0.9904 & $+7.91 \% \pm 9.44 \%$ & 0.3549 & $+15.67 \% \pm 12.65 \%$ & 0.1509 & $+4.28 \% \pm 5.70 \%$ & 0.443 \\
\hline $\mathrm{LDH}$ & $+0.08 \% \pm 7.92 \%$ & 0.9904 & $+4.48 \% \pm 5.35 \%$ & 0.3549 & $+8.89 \% \pm 7.17 \%$ & 0.1509 & $+2.42 \% \pm 3.22 \%$ & 0.443 \\
\hline Sodium & $+0.72 \% \pm 0.74 \%$ & 0.3054 & $+0.21 \% \pm 0.63 \%$ & $0.7 \mid 36$ & $-0.29 \% \pm 1.09 \%$ & 0.767 & $-0.11 \% \pm 0.38 \%$ & 0.7531 \\
\hline Phosphorus & $+1.92 \% \pm 5.25 \%$ & 0.6982 & $+3.95 \% \pm 3.35 \%$ & 0.21 & $+5.98 \% \pm 4.81 \%$ & 0.293 & $+2.45 \% \pm 2.01 \%$ & 0.2168 \\
\hline Progesterone & $-0.20 \% \pm 18.65 \%$ & 0.9904 & $-8.86 \% \pm 10.58 \%$ & 0.3549 & $-17.53 \% \pm 14.15 \%$ & 0.1509 & $-4.79 \% \pm 6.39 \%$ & 0.443 \\
\hline Mean & $+2.91 \% \pm 9591 \%$ & 0.6448 & $+4.39 \% \pm 9.81 \%$ & $0.294 I$ & $+5.88 \% \pm 11.93 \%$ & 0.2282 & $+2.93 \% \pm 6.29 \%$ & 0.3458 \\
\hline
\end{tabular}

The aim of this experimental study was to examine the effect of Epo on a rat model and particularly on a HR protocol. The effect of that molecule was studied by measuring the blood mean potassium (K) levels.

\section{Materials and methods}

\section{Animal preparation}

This experimental study was licensed by Veterinary Address of East Attiki Prefecture under 3693/12-11-2010 \&14/10-1-2012 decisions. All settings needed for the study including consumables, equipment and substances used, were a courtesy of Experimental Research Center of ELPEN Pharmaceuticals Co. Inc. S.A. at Pikermi, Attiki. Accepted standards of humane animal care were adopted for Albino female Wistar rats. Normal housing in laboratory 7 days before the experiment included continuous access to water and food. The experiment was acute which meant that awakening and preservation of the rodents was not following the experiment. They were randomly delivered to four experimental groups by 10 animals in each one. Hypoxia for 45 minutes followed by reoxygenation for 60 minute (group A). Hypoxia for 45 minutes followed by reoxygenation for 120minute (group B). Hypoxia for 45 minute followed by immediate Epo intravenous (IV) administration and reoxygenation for 60minute (group C). Hypoxia for 45 minute followed by immediate Epo IV administration and reoxygenation for 120 minute (group D). The molecule Epo dosage was $10 \mathrm{mg} / \mathrm{Kg}$ body weight of animals.
At first, the animals were submitted into prenarcosis followed by general anesthesia. The detailed anesthesiologic technique is described in related. ${ }^{2}$ Oxygen supply, electrocardiogram and acidimetry were continuously provided during whole experiment performance.

The protocol of HR was followed. Hypoxia was caused by forceps clamping the inferior aorta over renal arteries for 45 minutes and after laparotomic access had been achieved. Re-oxygenation was induced by removing the clamp and there establishment of the inferior aorta patency. The molecules were administered at the time of re-oxygenation, through inferior vena cava after catheterization had been achieved. The $\mathrm{K}$ levels measurements were performed within 60 minutes of reoxygenation (for groups $\mathrm{A}$ and $\mathrm{C}$ ) and at 120 minutes of re-oxygenation (for groups $\mathrm{B}$ and $\mathrm{D}$ ). The mean weight of the forty (40) female Wistar albino rats used was 247.7g (Std.Dev: 34.99172g), with min weight $\geq 165 \mathrm{~g}$ and max weight $<320 \mathrm{~g}$. The rats weight could be potentially a confusing factor, e.g. the more obese rats appear to have greater K levels. This suspicion was investigated.

\section{Model of hypoxia-re-oxygenation injury}

Control groups: 20 control rats (mean mass $252.5 \mathrm{~g}$ (Std. Dev: $39.31988 \mathrm{~g}$ ) suffered by hypoxia for 45 minutes followed by reoxygenation.

Group A: Re-oxygenation lasted for 60 minutes ( $\mathrm{n}=10$ controls rats) mean mass $243 \mathrm{~g}$ [Std. Dev: $45.77724 \mathrm{~g}$ ], mean potassium levels $6.85 \mathrm{mmol} / \mathrm{L}$ (Std. Dev: $0.8449194 \mathrm{mmol} / \mathrm{L}$ ) (Table 2). 
Table 2 Weight and potassium mean levels and Std. Dev. of groups

\begin{tabular}{llll}
\hline Groups & Variable & Mean & Std. Dev \\
& & & \\
\hline \multirow{2}{*}{ A } & Weight Potassium & $\begin{array}{l}243 \mathrm{~g}, \\
6.85 \mathrm{mmol} / \mathrm{l}\end{array}$ & $\begin{array}{l}45.77724 \mathrm{~g}, \\
0.8449194 \mathrm{mmol} / /\end{array}$ \\
& & $6.85 \mathrm{mmol} / \mathrm{l}$ & $31.10913 \mathrm{~g}$ \\
B & Weight Potassium & $262 \mathrm{~g}$ & $0.950789 \mathrm{mmol} / \mathrm{l}$ \\
& & $242.8 \mathrm{~g}$ & $29.33636 \mathrm{~g}$ \\
C & Weight Potassium & $6.44 \mathrm{mmol} / \mathrm{l}$ & $0.4742245 \mathrm{mmol} / /$ \\
& & $243 \mathrm{~g}$ & $32.84644 \mathrm{~g}$ \\
D & Weight Potassium & $6.94 \mathrm{mmol} / /$ & $0.5581715 \mathrm{mmol} / /$
\end{tabular}

Group B: Re-oxygenation lasted for 120 minutes ( $\mathrm{n}=10$ controls rats) mean mass 262g [Std. Dev: 31.10913g], mean potassium levels 6.82 mmol/L (Std. Dev: 0.9507891mmol/L) (Table 2).

\section{Erythropoietin group}

20 Epo rats (mean mass $242.9 \mathrm{~g}$ (Std. Dev: $30.3105 \mathrm{~g}$ ) suffered by hypoxia for 45 minutes followed by reoxygenation in the beginning of which $10 \mathrm{mg}$ Epo/kg body weight were IV administered.

Group C: Re-oxygenation lasted for 60 minutes ( $\mathrm{n}=10$ Epo rats) mean mass 242.8g [Std. Dev: 29.33636g], mean potassium levels 6.44mmol/L (Std. Dev: 0.4742245mmol/L) (Table 2).

Group D: Re-oxygenation lasted for 120 minutes ( $\mathrm{n}=10$ Epo rats) mean mass 243g (Std. Dev: 32.84644g), mean potassium levels 6.94mmol/L (Std. Dev: 0.5581715mmol/L) (Table 2).

Statistical analysis: Weight comparison of everyone from 4 rats groups initially was performed with each other from 3 remaining groups applying statistical paired t-test (Table 3). Any emerging significant difference among $\mathrm{K}$ levels was investigated whether owed in the above-mentioned significant weight correlations. K levels comparison of every one the 4 rats groups was initially performed with each other from the above mentioned 3 remaining groups applying statistical paired t-test (Table 3). The application of generalized linear models $(\mathrm{glm})$ with the dependant $\mathrm{K}$ level variable and independent variables namely, the Epo administration or no, the reoxygenation time and their interaction, was followed. Inserting the rats weight as an independent variable at glm, a non significant relation turns on potassium levels $(\mathrm{p}=0.0525)$, which justifies that further investigation is not needed.

\section{Results}

The glm application resulted in: Erythropoietin administration decreased the potassium levels insignificantly by $0.145 \mathrm{mmol} / \mathrm{L}(-0.6168402 \mathrm{mmol} / \mathrm{L}-0.3268402 \mathrm{mmol} / \mathrm{l})(\mathrm{P}=0.5376)$, also in accordance with paired t-test $(\mathrm{P}=0.4893)$.

Reoxygenation time increased the potassium levels insignificantly by $0.235 \mathrm{mmol} / 1(-0.2329153 \mathrm{mmol} / \mathrm{l}-0.7029154 \mathrm{mmol} / \mathrm{l})(\mathrm{P}=0.3157)$, also in accordance with paired t-test $(\mathrm{P}=0.3592)$. The interaction of erythropoietin administration and reoxygenation time increased the potassium levels in significantly by $0.0118182 \mathrm{mmol} / \mathrm{L}(-$ $0.2741311 \mathrm{mmol} / \mathrm{L}-0.2977674 \mathrm{mmol} / \mathrm{L})(\mathrm{P}=0.9338)$. Reviewing the above and Table $3-5$ sum up concerning the alteration influence of erythropoietin in connection with reoxygenation time. These observations indicate a short-term miscellaneous effect of Epo on potassium levels. That effect ought not to be into consideration for their biological or clinical impacts, since the results are nonsignificant. Another trial must be held providing pure alteration direction and significant results.

\section{Discussion}

Bibliography lacks references concerning whether hypoxia can influence the potassium levels. Potassium levels influence,,$^{3-5}$ multiple physiological processes, including resting cellular-membrane potential and the propagation of action potentials in neuronal, muscular, and cardiac tissue. ${ }^{6}$ Also $\mathrm{K}$ influences the hormone secretion and action, the vascular tone, controls the systemic blood pressure and the gastrointestinal motility. It joins in acid-base homeostasis, in glucose and insulin metabolism, in mineralocorticoid action, in renal concentrating ability and in fluid and electrolyte balance. Isolated potassium administration is impossible due to its feature to have a single electron in its outer electron shell, which readily gives up to create an atom with a positive charge - a cation and oxidizes rapidly in air and reacts vigorously with water combining with anions to form salts. Potassium occurs only in ionic salts usually associated with another drug or a factor. This last chemical conjugate probably influences the potassium occurrence. So, the administration of potassium is by means of a salt.

Chiu et al. ${ }^{7}$ enhanced the protein kinase $\mathrm{C}-\varepsilon$ potassium assisted translocation (PKC) from the cytosol to mitochondria in rat myocardium, with resultant inhibition of the mitochondrial permeability transition through the opening of mitochondrial $\mathrm{K}$ (ATP) channels, affording protection against myocardial ischemiareperfusion (IR) injury by the herbal Danshen-Gegen decoction formulation. Kuhrt et $\mathrm{al}^{8}{ }^{8}$ found a decrease in the expression of inwardly rectifying potassium (Kir) currents, is a characteristic feature of retinal glial (Müller) cells after transient retinal ischemia. During 4 days in vitro, Müller cells displayed a decrease in Kir currents and an increase in transient A-type potassium currents, which was similar to IR in vivo. Nossaman et al. ${ }^{9}$ showed that the free radical peroxynitrite (ONOO-) has significant vasodilator activity in the hind limb vascular bed of the cat mediated by a cGMP- dependent mechanism. ${ }^{9}$ Pollesellop et al. ${ }^{10}$ have shown that levosimendan has ${ }^{10}$ vasodilatory and anti ischemic effects mediated via the opening of ATP-sensitive $\mathrm{K}$ channels in vascular smooth-muscle cells and also acts on mitochondrial ATP-sensitive K (mito KATP) channels, an action thought to protect the heart against IR damage. Chicco et al. ${ }^{11}$ abolished the sarcolemmal K (ATP) channel blockade traininginduced cardio protection increasing infarct size to $47.5 \pm 3.5 \%$ of zone at risk (ZAR) in rats. This study demonstrates that resistance to myocardial IR injury is dependent on sarcolemmal K (ATP) activity during ischemia.

Garcia Gonzalez et al. ${ }^{12}$ have shown that levosimendan exerts a coronary and systemic vasodilatory effect through its ATPdependent K channel K (ATP) opening properties, as was experienced in patients with cardiogenic shock. ${ }^{12}$ Bittner et al. ${ }^{13}$ used either EuroCollins-aprotinin procurement solution (Apt-EC group) or aprotinin in combination with low $-\mathrm{K}$ dextran (LPD) flush solution (AptLPD group) for the procurement of donor lungs. ${ }^{13}$ The associated mortality rate was $40 \%$. There was no mortality in the Apt-EC group and one patient died in the Apt-LPD group due to PTRI- induced graft failure. Severe PTRI increased short-term morbidity and mortality. Reines et al. ${ }^{14}$ isolated from rat cerebral IR cortex an 
endogenous $\mathrm{Na}(+), \mathrm{K}(+)$-ATPase inhibitor, termed endobain $\mathrm{E}$ (approximately $80 \mathrm{mg}$ original tissue). ${ }^{14}$ Its effect on synaptosomal membrane $\mathrm{Na}(+)$, and $\mathrm{K}(+)$-ATPase activity binding to cerebral cortex membranes, was found that the endogenous modulator isolated from IR rats was able to inhibit both enzyme activity and ligand binding. Müllenheim et al ${ }^{15}$ found that racemic ketamine blocks ${ }^{15} \mathrm{~K}$ (ATP) channels in isolated cells and abolishes short-term cardio protection against prolonged ischemia. All rabbits were then subjected to coronary IR but controls without ischemic late preconditioning LPC and the drugs $(10 \mathrm{mg} / \mathrm{kg})$ were given 10 minutes before IR. Racemic ketamine, but not $\mathrm{S}(+)$-ketamine, blocks the cardio protection induced by ischemic late preconditioning. Reshef et al ${ }^{16}$ studied the effect of opening and blocking of ATP-sensitive potassium (K (ATP)) channels in a model of primary rat neuronal cultures, subjected to metabolic IR. ${ }^{16}$ The metabolic poisoning resulted in a marked decrease in cellular ATP content by 3 -fold. In the neurons, the opening of the K (ATP) channels confers protection against an ATP-depleting crisis. Schmidt et al. ${ }^{17}$ measured Na, K-ATPase concentration more effectively from various parts stable during IR, of porcine and canine myocardium. ${ }^{17}$ A relationship between higher concentration of $\mathrm{Na}, \mathrm{K}$-ATPase and larger pressure work is suggested.

A majority of the following examples concern the influence of $\mathrm{K}$ levels fluctuation on Epo and a minority the reverse influence. Vac halp et al. ${ }^{18}$ found that the spirooxindoles optimized for PK/ PD profile (short-acting prolyl hydroxylase (PHD1) inhibitors). ${ }^{18}$ $\mathrm{K}$ channel off-target activity (hERG) was successfully eliminated. Spiro hydantoins represent a class of short-acting PHD1-3 inhibitors causing a robust Epoup-regulation in vivo treating anemia. Zhang et al. ${ }^{19}$ carried out systematic optimization of parameters in the existence of cations. ${ }^{19}$ A convenient and sensitive determination of rHuEPOalpha with a LOD of $0.4 \mathrm{Nm}$ was achieved. Tringalig et al. ${ }^{20}$ found that increased levels of Epo in the hypothalamus may play ${ }^{20}$ a role in the control of hypothalamo-pituitary-adrenal (HPA) function modulating CRH release. Epo effects were studied in short- term (1-3h) experiments under basal conditions or after stimulation with $56 \mathrm{Mm} \mathrm{KCl}$. Moreover, Epo, inhibited $\mathrm{KCl}$. Epo effects were not mediated by modification of CRH gene expression, either in the absence or the presence of $\mathrm{KCl}$; in this paradigm, $\mathrm{KCl}$ per se did not modify $\mathrm{CRH}$ gene expression. Epo contributes to the regulation of the HPA axis activation in pathological conditions such as brain ischemia. Casino et al. ${ }^{21}$ analyzed serum $\mathrm{K}$ with the following guideline based targets: $3.5-6.0 \mathrm{mmol} / \mathrm{L}$. They suggested a systematic search of the well-known factors that could affect each CPM, for each failed patient. As an example, they screened all patients associated with inadequate responses to epoetin treatments. Ksiazek et al. ${ }^{22}$ found insignificant statistical differences in $\mathrm{K}$ clearance of intermittent peritoneal dialysis (IPD) patients before and after correction of anemia with ( $\mathrm{rHuEPO}$ ) therapy. Mohini R. ${ }^{23}$ promoted an increase in ingestion of more $\mathrm{K}$ correcting anemia in (end-stage renal disease) ESRD patients. ${ }^{23}$ Experience with patients receiving rHuEPO demonstrates that high-flux short-time hemodialysis is effective without significant differences between $\mathrm{K}$ groups.

Bahloul et al. ${ }^{24}$ associated poor prognosis in the ICU with the presence of circulatory failure (shock) and thrombocytopenia. ${ }^{24}$ Hypoxemia with $\mathrm{PaO}(2) / \mathrm{FiO}(2)<200$ is among the predictive factors of pulmonary embolism (PE) in post-traumatic critically ill patients. Prevention is highly warranted. Bahloul et al. ${ }^{25}$ also associated PE with a high ICU and in-hospital mortality rate, including hypoxemia with
$\mathrm{PaO}(2) / \mathrm{FiO}(2)<300$ among predictive factors of PE. ${ }^{25}$ Sun et al. ${ }^{26}$ found severe acute respiratory distress syndrome as the most common manifestation in critically ill patients with 2009 influenza A H1N1 infection in adult. ${ }^{26}$ Failure to obtain satisfactory oxygenation with high-level ventilation settings within the first 7-days, onset of acute kidney injury and barotrauma, and continuous need for vasopressors portend a poor prognosis. Díez-Tejedor et al. ${ }^{27}$ suggested treatment of increased plasma glucose levels, although a clinical trial of glucoseinsulin-potassium infusions is ongoing. ${ }^{27}$ Moreover, insulin therapy in critically ill patients, including stroke patients, is safe and determines lower mortality and complication rates. Hypoxemia also worsens the stroke prognosis, and oxygen therapy in case of $<92 \% \mathrm{O}_{2}$ saturation is recommended. This could help to save more brain tissue to get the best conditions for further specific stroke therapies such as the use of neuroprotective or thrombolytic drugs in the hospital.

\section{Conclusion}

Erythropoietin administration, re oxygenation time and their interaction have miscellaneous insignificant effects on potassium levels on the narrow context of 2 hours. Perhaps, a longer study time or a higher Epo dose may have clearer and significant effects.

\section{Acknowledgments}

None.

\section{Conflicts of interest}

The author declares no conflict of interest.

\section{References}

1. Li C, Jackson RM. Reactive species mechanisms of cellular hypoxiareoxygenation injury. Am J Physiol Cell Physiol. 2002;282(2):C227C241.

2. Tsompos C, Panoulis C, Toutouzas K, et al. A The Effect of Erythropoietin on Urea Levels during Ischemia Reperfusion Injury in Rats Literati. Journal of Pharmaceutical Drug Delivery Technologies. 2015;1(2):61-64.

3. Malnic G, Giebisch G, Muto S, et al. Regulation of $\mathrm{K}^{+}$excretion. In: Alpern RJ, et al. editors. Seldin and Giebisch's the kidney: physiology and Pathophysiology. England, London: Academic Press; 2013:16591716.

4. Mount DB, Zandi-Nejad K. Disorders of potassium balance. In: Taal MW, et al. editors. The kidney: Philadelphia, USA: Elsevier; 2012:640688.

5. Lockless SW, Zhou M, MacKinnon R. Structural and thermodynamic properties of selective ion binding in a $\mathrm{K}^{+}$channel. PLoS Biol. 2007;5(5):e121.

6. Linus S, Wingo CS. Disorders of potassium metabolism. In: Freehally J, et al. editors. Comprehensive clinical nephrology. St Louis, USA: Saunders; 2014:118.

7. Chiu PY, Wong SM, Leung HY, et al. Acute treatment with DanshenGegen decoction protects the myocardium against ischemia/ reperfusion injury via the redox-sensitive $\mathrm{PKC} \varepsilon / \mathrm{mK}(\mathrm{ATP})$ pathway in rats. Phytomedicine. 2011;18(11):916-925.

8. Kuhrt H, Wurm A, Karl A, et al. Müller cell gliosis in retinal organ culture mimics gliotic alterations after ischemia in vivo. Int $J$ Dev Neurosci. 2008;26(7):745-751. 
9. Nossaman BD, Bivalacqua TJ, Champion HC, et al. Analysis of vasodilator responses to peroxynitrite in the hind limb vascular bed of the cat. J Cardiovasc Pharmacol. 2007;50(4):358-366.

10. Pollesello P, Papp Z. The cardioprotective effects of levosimendan preclinical and clinical evidence. $J$ Cardiovasc Pharmacol. 2007;50(3):257-263

11. Chicco AJ, Johnson MS, Armstrong CJ, et al. Sex-specific and exercise-acquired cardioprotection is abolished by sarcolemmal KATP channel blockade in the rat heart. Am J Physiol Heart Circ Physiol. 2007;292(5):H2432-H2437.

12. García González MJ, Domínguez RA. Pharmacologic treatment of heart failure due to ventricular dysfunction by myocardial stunning: potential role of levosimendan. Am J Cardiovasc Drugs. 2006;6(2):69-75.

13. Bittner H, Richter M, Kuntze T, et al. Aprotinin decreases reperfusion injury and allograft dysfunction in clinical lung transplantation. Eur $J$ Cardiothorac Surg. 2006;29(2):210-215.

14. Reinés A1, Zárate S, Carmona C, et al. Endobain E, a brain endogenous factor, is present and modulates NMDA receptor in ischemic conditions. Life Sci. 2005;78(3):245-252.

15. Müllenheim J, Rulands R, Wietschorke T, et al. Late preconditioning is blocked by racemic ketamine, but not by $\mathrm{S}(+)$-ketamine. Anesth Analg. 2001;93(2):265-270.

16. Reshef A, Sperling O, Zoref-Shani E. Opening of ATP-sensitive potassium channels by cromakalim confers tolerance against chemical ischemia in rat neuronal cultures. Neurosci Lett. 1998;250(2):111-114.

17. Schmidt TA, Svendsen JH, Kjeldsen K, et al. Quantification of the total $\mathrm{Na}, \mathrm{K}-\mathrm{ATPase}$ concentration in atria and ventricles from mammalian species by measuring $3 \mathrm{H}$-ouabain binding to intact myocardial samples. Stability to short term ischemia reperfusion. Basic Res Cardiol. 1990;85(4):411-427.

18. Vachal P, Miao S, Pierce JM, et al. 1,3,8-Triazaspiro[4.5]decane-2,4diones as efficacious pan-inhibitors of hypoxia-inducible factor prolyl hydroxylase 1-3 (HIF PHD1-3) for the treatment of anemia. $J$ Med Chem. 2012;55(7):2945-2959.
19. Zhang Z, Guo L, Tang J, et al. An aptameric molecular beacon-based Signal-on approach for rapid determination of rHuEPO-alpha. Talanta. 2009;80(2):985-990.

20. Tringali G, Pozzoli G, Lisi L, et al. Erythropoietin inhibits basal and stimulated corticotropin-releasing hormone release from the rat hypothalamus via a nontranscriptional mechanism. Endocrinol. 2007;148(10):4711-4715.

21. Casino FG, Lopez T. Regional clinical audit, guideline targets, and local and regional benchmarks. G Ital Nefrol. 2005;22(1):37-46.

22. Ksiazek A, Baranowska-Daca E. Hematocrit influence on peritoneal dialysis effectiveness during recombinant human erythropoietin treatment in patients with chronic renal failure. Perit Dial Int. 1993;13(2):S550-S552.

23. Mohini R. Clinical efficacy of recombinant human erythropoietin in hemodialysis patients. Semin Nephrol. 1989;9(1):16-21.

24. Bahloul M, Chaari A, Dammak H, et al. Post-traumatic pulmonary embolism in the intensive care unit. Ann Thorac Med. 2011;6(4):199206.

25. Bahloul M, Chaari A, Kallel H, et al. Pulmonary embolism in intensive care unit: Predictive factors, clinical manifestations and outcome. Ann Thorac Med. 2010;(2):97-103.

26. Sun JJ, Li C, Wu DW, et al. Eighteen cases of 2009 influenza A H1N1 associated with respiratory failure in adults. In: Zhongguo Wei, Zhong, Bing Ji, et al, editors. 2010;22(3):156-160.

27. Díez TE, Fuentes B. Acute care in stroke: the importance of early intervention to achieve better brain protection. Cerebrovasc Dis 2004;17(1):130-137. 